\title{
Student oriented implementation of SVPWM using LabVIEW and myRio
}

This paper was downloaded from TechRxiv (https://www.techrxiv.org).

\section{LICENSE}

$\mathrm{CCO}$

SUBMISSION DATE / POSTED DATE

23-02-2022 / 01-03-2022

\section{CITATION}

Shami, Muhammad Arsalan; Chaudhary, Muhammad Ali; Khan, Eeman Ahmed; Zulfiqar, Anum (2022): Student oriented implementation of SVPWM using LabVIEW and myRio. TechRxiv. Preprint. https://doi.org/10.36227/techrxiv.19219944.v1

DOI

10.36227/techrxiv.19219944.v1 


\title{
Student oriented implementation of SVPWM using LabVIEW and myRio
}

\author{
Muhammad Arsalan Shami, Muhammad Ali, Eeman Ahmed, Anum Zulfiqar, Dr. Syed Abdul Rahman Kashif, \\ Muhammad Anique Aslam
}

\begin{abstract}
Contribution: An approach for helping undergraduate students understand complex algorithms through structured flowcharts (SFCs) and their implementation using graphical programming (GPR) on LabVIEW and myRio.

Background: Space vector pulse width modulation (SVPWM) is an important algorithm for students studying power electronics. But, when studying this algorithm, a lot of students often find difficulty in comprehending it.

Intended Outcomes: A method which helps students understand SVPWM easily and enables them to implement it on hardware with less difficulty. This article also intends to show the effectiveness of LabVIEW and myRio as constructive educational tools. The proposed approach can also be applied to teaching other complex algorithms.

Application Design: The proposed approach makes use of SFCs to help students develop a theoretical foundation of SVPWM in a theory class. The theory session is followed by the practical implementation of SVPWM using GPR on LabVIEW and testing it on a test-bed (a 3-phase motor connected to myRio) in two laboratory session.
\end{abstract}

Index Terms-SVPWM, LabVIEW, myRio, Structured Flowchart, Graphical Programming.

\section{INTRODUCTION}

$\mathbf{S}$ PACE vector pulse width modulation (SVPWM) is an important concept for undergraduate students studying power electronics as it is one of the most effective inversion techniques for power electronics converters [1]. But, because of its complexity - its numerous steps, convoluted data flow and tedious computations, students often find it very difficult to comprehend. Furthermore, students find it quite challenging to implement it on a microprocessor for power electronics applications as they have not developed a solid theoretical foundation of the algorithm. One way to resolve this issue is to make use of structured flow charts (SFCs) and graphical programming (GPR).

Structured flowcharts aid algorithm comprehension [2]. They are effective teaching tools and serve to reveal students' difficulties in understanding algorithmic concepts [3]. Studies have shown that flowcharts can be very effective for visual learners in understanding algorithms as well as writing them [4]. Furthermore, the results of a study published in [5] show that a vast majority of students prefer SFCs to pseudocode for algorithm comprehension. Thus, flowcharts can be employed to help students understand the concepts of SVPWM.

As far as implementation of complex algorithms is concerned, the SFCs of these algorithms can also be employed to develop their respective codes in graphical programming format. Students often prefer to express their algorithms in graphical coding format than employing traditional coding methods [6]. One of the reasons maybe that as the complexity of an algorithm increases so does the need for graphical depiction [7]. There are a number of advantages as mentioned in a detailed study in [8] where a series of experiments were conducted to assess the flowchart's effectiveness in constructing, debugging, comprehending, and modifying programs. Moving from a concept studied in SFC to GPR is advantageous as it enables students to develop algorithms gradually from the initial interaction flow diagrams instead of jumping from theory to programming [9]. Using SFCs and GPRs not only improve the students' computational thinking skills and programming self-efficacy, but also help them to achieve better academic outcomes [10].

\section{GRP ENVIRONMENTS FOR IMPLEMENTING SFCS}

Programming environments which offer GPR use some kind of graphical representation of data types, variables and control structures. In these enviroments coding is accomplished with a syntax-directed editor [11]. In the integrated development environments (IDEs) which support GPR, the technology of software visualization is utilized [12] and its main aim is facilitating the understanding of algorithmic concepts.

These environments offer a number of advantages such as object oriented programming, running through the program automatically, synchronized execution of flowchart and corresponding source code, explanatory visualization, and even web based applications and collaborative activities [13]. But, as mentioned before, the main aim is facilitating the understanding of algorithmic concepts. In fact, in the case of iconic programming languages that are used for developing programs with the form - usually - of a flowchart, attention is focused on developing problem solving skills ( [14], [15], [16]). These environments give the students a chance to focus on the structure and design of algorithms rather than being stuck on syntax. In addition to this, using visual programming is beneficial as it reduces the time students spend on correcting errors in their code and, thus, allows students to focus more on the problem solving activities while producing a working program [17].

Therefore, graphical coding can also be utilized in implementing SVPWM.

\section{A. LabVIEW - A GPR tool}

There are a number of graphical languages available. Among those, LabVIEW from National Instruments is one 
of the most convenient for students [18] and can be utilized for graphical programming of SVPWM. Furthermore, to see this algorithm in action, myRio FPGA (also from National Instruments) can be used as an adjunct to LabVIEW.

LabVIEW is a very helpful tool for understanding complex algorithm, such as SVPWM, mainly because of two reasons [19]. The first is LabVIEW's fast and intensive hardware integration with FPGA-based embedded hardware and the second is its graphical approach to programming which allows programming using a flowchart like method, called graphical data flow, to move data from one function to another. LabVIEW represents parallelism in the compiled code and its graphical nature makes it very easy to visualize [19].

The myRio FPGA board is quite compatible with LabVIEW. Through LabVIEW, the GPIO pins of myRio can be configured with ease and register level encoding of microprocessor can be avoided. The data flow between LabVIEW and myRio is seamless which allows a user to input data to writable variables and visualize real time data from myRio on LabVIEW in form of graphs to understand the system's response to various inputs. LabVIEW comes equipped with core engineering IPs such as Fast Fourier Transforms along with a host of a number of specialty algorithms [19] available as add-ons. All of these tools are compatible and quickly combinable. These easy to use tools can be used to perform a number of tasks including harmonic analysis of signals.

This paper is for educational purposes. The intention is not to produce a high end industrial product rather it is to show how to make a complex algorithm, such as SVPWM, using laboratory resources. If undergraduate students want to understand and produce SVPWM in a laboratory using the limited laboratory resources then LabVIEW and myRio can be employed.

\section{SySTEM DESIGN}

The design to teach this particular algorithm includes a 3 hour theory session followed by two 3 hour laboratory sessions.

\section{A. Theory}

In the theory session, students are taught the fundamentals of SVPWM from [1]. Here, the students are shown the derivation of various mathematical equations which are involved in this algorithm. It would be evident from the theoretical discussion that SVPWM has a lot of calculations involved. The main challenge is understanding the synchronization of the flowing data. All this adds to the difficulty of the undergraduate student to understand SVPWM. An emphasis, thus, is made on the SFC of SVPWM generation (as shown in Figure 1) since understanding complex algorithms through flowcharts is easier for a student [3]. One other reason for focusing on the SFC is that the students will follow the given SFC and reproduce the code of SVPWM in a laboratory session following the same underlying model of SFC.

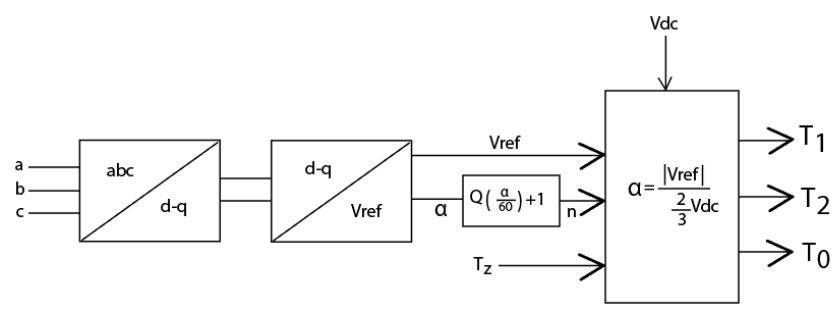

Fig. 1: SFC of SVPWM

\section{B. Laboratory session 1}

In the first laboratory session, students develop the code of SVPWM on LabVIEW in GPR following the SFC which was taught in the theory session. They are given a chance to simulate and evaluate their code to remove errors, if any. The code is given in Section IV-A2 with a brief explanation.

\section{Laboratory session 2}

In the second laboratory session, the codes developed by the students are run on a test bed to demonstrate the hardware implementation of SVPWM. This code on LabVIEW can be easily uploaded on myRio [19]. The SVPWM is applied to a gate driver (connected to a 3-phase inverter) through myRio to control the speed of a 750 Watt induction motor being controlled through vector control (more specifically field oriented control (FOC)).

\section{IMPLEMENTATION OF SVPWM}

The hardware and software implementation of SVPWM is presented in this section. As mentioned before, the code of SVPWM is written in a GPR format on LabVIEW following its SFC. This code is then applied to a motor drive to demonstrate its practical hardware application.

\section{A. Software implementation}

1) SFC of SVPWM on LabVIEW: The flow chart shown in Figure 2 is the process through which SVPWM generated on LabVIEW is used to control a motor drive though myRio. The code of SVPWM is generated on LabVIEW by the user in graphical coding format. This code is converted from graphics to Verilog by LabVIEW and is fed to myRio. The myRio, after receiving this code, uses it to generate gate pulses which in turn control the motor drive.

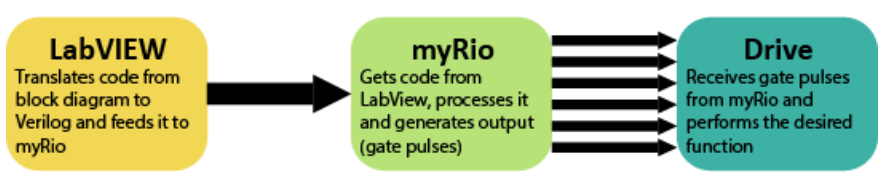

Fig. 2: SFC of SVPWM on LabVIEW

2) Code of SVPWM on LabVIEW: The code of SVPWM developed on LabVIEW is presented in this section. The code was designed on LabVIEW because all the blocks used are synchronized and data flow can be easily observed [19] facilitating a student in understanding this algorithm more than 


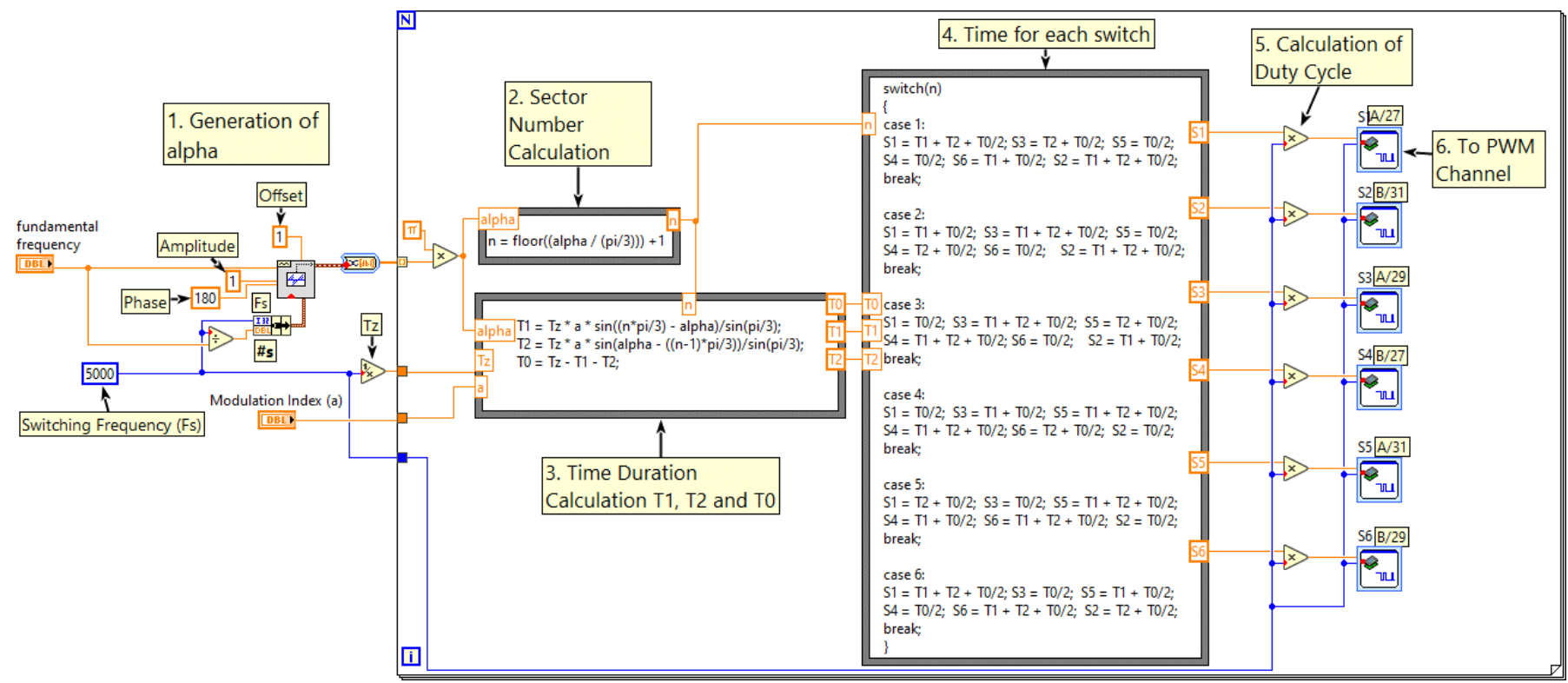

Fig. 3: Code of SVPWM on LabVIEW

traditional syntax based coding. It must be noted that it is being assumed that this code of SVPWM is part of a larger system which is the field oriented control system. The FOC provides with two values namely fundamental frequency $f$ and modulation index $a$. So, for the sake of development of this code, these two values, $f$ and $a$, are being input by the code developer.

The implementation of SVPWM comprises of sector identification, calculation of switching time, evaluation of switching vector and the "best choice" of switching order for the vectors of the inverter voltage [20]. The procedure for generating SVPWM includes the following parts:

1) Generation of $\alpha$.

2) Sector number $(n)$ calculation.

3) Time duration calculation $T_{1}, T_{2}$ and $T_{0}$.

4) Time for each switch ( $S_{1}$ to $\left.S_{6}\right)$

5) Calculation of duty cycle $D$.

6) PWM channels.

The code written in LabVIEW is depicted in Figure 3.

a) Generation of $\alpha$ : First of all, a sawtooth wave is generated having an amplitude of 1 and an offset of $1 . \alpha$ is produced in terms of samples of $\alpha$ in a circle. Thus, there is a direct relation of the number of samples of $\alpha$ and the samples of sawtooth generated. The number of samples of the sawtooth has to be related to switching frequency $F s$ and fundamental frequency $f$ with the following relationship in (1)

$$
\#_{s}=\frac{F_{s}}{f}
$$

where $\#_{s}=$ Number of samples of $\alpha$

This way we obtain values from 0 to $2 \pi$ and a circle is completed.

b) Sector number (n) calculation: The next step is calculation of the sector number (n) of the generated $\alpha$ which is done according to (2).

$$
n=\text { floor }\left(\frac{\alpha}{\frac{\pi}{3}}\right)+1
$$

c) Time duration calculation $T_{1}, T_{2}$ and $T_{0}$ : The third step is the computation of time duration $T_{1}, T_{2}$ and $T_{0}$. This is done according to equations (3), (4) and (5).

$$
\begin{gathered}
T_{1}=T_{z} \cdot a \cdot \frac{\sin \left(\frac{n \pi}{3}\right)-\alpha}{\sin \left(\frac{\pi}{3}\right)} \\
T_{2}=T_{z} \cdot a \cdot \frac{\sin \left(\alpha-\left(\frac{(n-1) \pi}{3}\right)\right.}{\sin \left(\frac{\pi}{3}\right)} \\
T_{0}=T_{z}-T_{1}-T_{2}
\end{gathered}
$$

Where $a$ is the modulation index and $\mathrm{T}_{z}$ is the switching time defined as $\mathrm{T}_{z}=\frac{1}{F_{s}}$

d) Time for each switch $\left(S_{1}\right.$ to $\left.S_{6}\right)$ : The next step is computing the time of the six transistor switches, $S_{1}, S_{2}, S_{3}$, $S_{4}, S_{5}$ and $S_{6}$, under the configuration of the inverter. This depends upon the sector number and time durations $T_{1}, T_{2}$ and $T_{0}$. The calculations of time for switches are according to Table I.

TABLE I: The switch ON time for each sector

\begin{tabular}{lcccccc}
\hline Sectors & $\mathrm{S}_{1}$ & $\mathrm{~S}_{2}$ & $\mathrm{~S}_{3}$ & $\mathrm{~S}_{4}$ & $\mathrm{~S}_{5}$ & $\mathrm{~S}_{6}$ \\
\cline { 2 - 7 } & $\mathrm{sec}$ & $\mathrm{sec}$ & $\mathrm{sec}$ & $\mathrm{sec}$ & $\mathrm{sec}$ & sec \\
\hline 1 & $\mathrm{~T}_{1}+\mathrm{T}_{2}+\mathrm{T}_{0} / 2$ & $\mathrm{~T}_{1}+\mathrm{T}_{2}+\mathrm{T}_{0} / 2$ & $\mathrm{~T}_{2}+\mathrm{T}_{0} / 2$ & $\mathrm{~T}_{0} / 2$ & $\mathrm{~T}_{0} / 2$ & $\mathrm{~T}_{1}+\mathrm{T}_{0} / 2$ \\
2 & $\mathrm{~T}_{1}+\mathrm{T}_{0} / 2$ & $\mathrm{~T}_{1}+\mathrm{T}_{2}+\mathrm{T}_{0} / 2$ & $\mathrm{~T}_{1}+\mathrm{T}_{2}+\mathrm{T}_{0} / 2$ & $\mathrm{~T}_{2}+\mathrm{T}_{0} / 2$ & $\mathrm{~T}_{0} / 2$ & $\mathrm{~T}_{0} / 2$ \\
3 & $\mathrm{~T}_{0} / 2$ & $\mathrm{~T}_{1}+\mathrm{T}_{0} / 2$ & $\mathrm{~T}_{1}+\mathrm{T}_{2}+\mathrm{T}_{0} / 2$ & $\mathrm{~T}_{1}+\mathrm{T}_{2}+\mathrm{T}_{0} / 2$ & $\mathrm{~T}_{2}+\mathrm{T}_{0} / 2$ & $\mathrm{~T}_{0} / 2$ \\
4 & $\mathrm{~T}_{0} / 2$ & $\mathrm{~T}_{0} / 2$ & $\mathrm{~T}_{1}+\mathrm{T}_{0} / 2$ & $\mathrm{~T}_{1}+\mathrm{T}_{2}+\mathrm{T}_{0} / 2$ & $\mathrm{~T}_{1}+\mathrm{T}_{2}+\mathrm{T}_{0} / 2$ & $\mathrm{~T}_{2}+\mathrm{T}_{0} / 2$ \\
5 & $\mathrm{~T}_{2}+\mathrm{T}_{0} / 2$ & $\mathrm{~T}_{0} / 2$ & $\mathrm{~T}_{0} / 2$ & $\mathrm{~T}_{1}+\mathrm{T}_{0} / 2$ & $\mathrm{~T}_{1}+\mathrm{T}_{2}+\mathrm{T}_{0} / 2$ & $\mathrm{~T}_{1}+\mathrm{T}_{2}+\mathrm{T}_{0} / 2$ \\
6 & $\mathrm{~T}_{1}+\mathrm{T}_{2}+\mathrm{T}_{0} / 2$ & $\mathrm{~T}_{2}+\mathrm{T}_{0} / 2$ & $\mathrm{~T}_{0} / 2$ & $\mathrm{~T}_{0} / 2$ & $\mathrm{~T}_{1}+\mathrm{T}_{0} / 2$ & $\mathrm{~T}_{1}+\mathrm{T}_{2}+\mathrm{T}_{0} / 2$ \\
\hline
\end{tabular}

e) Calculation of duty cycle D: The next step is the calculations of duty cycles which is done with (6)

$$
D_{i}=S_{i} * F_{s}
$$

where $i=1,2, . .6$ 
f) PWM channels: PWM channels are fed with duty cycle $D$ and switching frequency $F_{s}$.

\section{B. Hardware implementation}

For the purpose of practical implementation, the SVPWM, generated through LabVIEW and myRio, is applied to run a 750 Watt 4-pole motor through an inverter connected to a gate driver. This motor drive is controlled through FOC. The SFC of the practical implementation is shown in Figure 4.

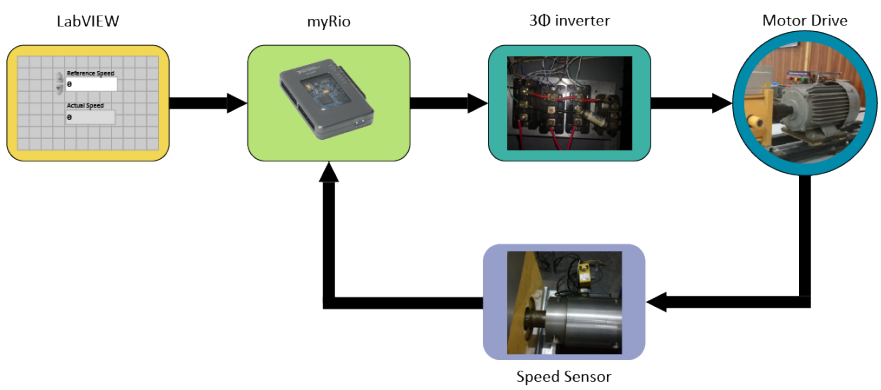

Fig. 4: SFC of practical implementation of SVPWM

The desired motor speed Reference Speed is input by the user in the graphics panel of LabVIEW. This value is sent to myRio which in turns performs calculations and controls the inverter. This inverter then controls the response i.e. speed of the motor. Finally, a hall effect based speed sensor measure the actual speed of the motor. This sensor acts as a feedback and feeds Actual Speed to myRio for further processing.

The test bed is shown in Figure 5.

\section{RESUlts AND Discussions}

The simulated and practical results of SVPWM along with the results of application on motor drive are shown and discussed in this section.

The developed code was run on a test setup in both open loop and close loop. In open loop, the values of frequency $f$ and modulation index $a$ were taken as input from the user. In close loop, the developed code was converted into a subsystem of FOC.

\section{A. Simulated and practical results of SVPWM}

The simulated and practical results of SVPWM are presented in Figure 6 and Figure 7 respectively. Both of these figures show duty cycle generated through the SVPWM algorithm at varying values of modulation index and a fixed frequency. The values of modulation index were kept at 0.3 , 0.5 and 0.7 while frequency was kept at $50 \mathrm{~Hz}$. It can be observed that as the value of modulation index increased, the amplitude of duty cycle also increased with no effect on the frequency.

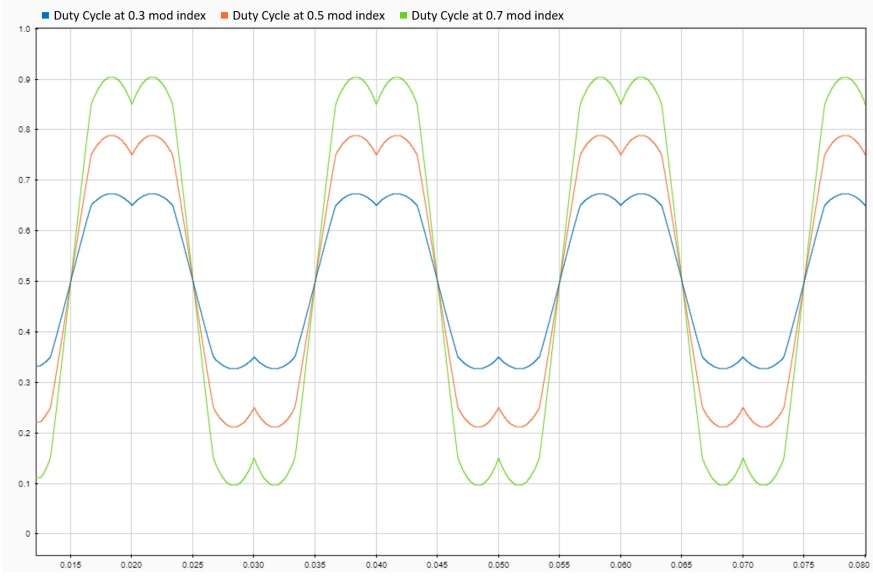

Fig. 6: Simulated results of duty cycle

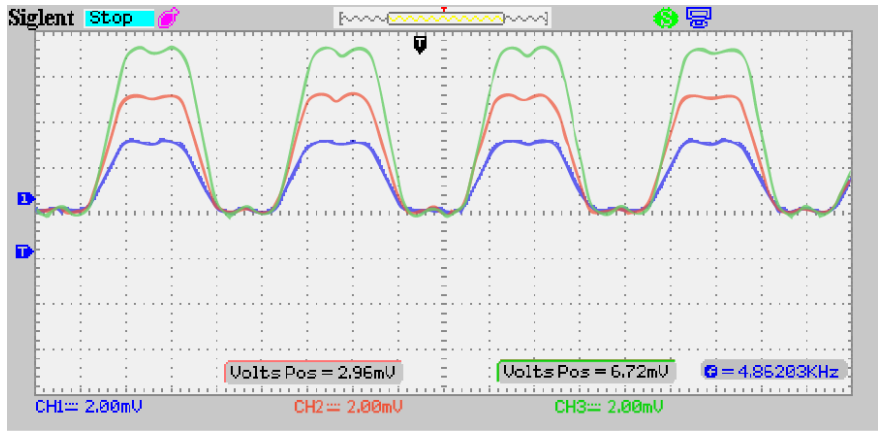

Fig. 7: Practical results of duty cycle
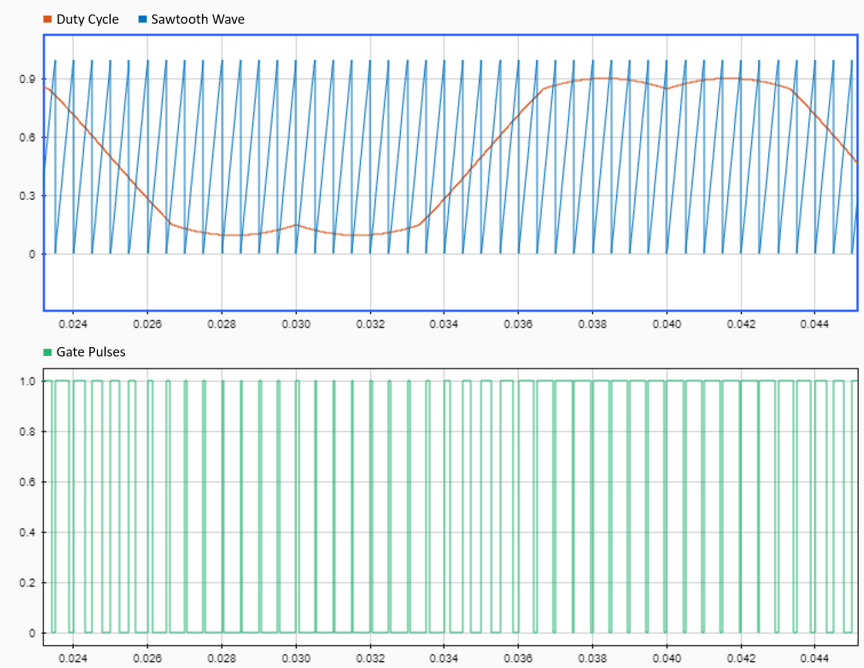

Fig. 8: Conversion of duty cycle into gate signals

\section{B. Conversion of duty cycle into gate pulses}

The generated duty cycle is converted into gate signals through a sawtooth wave comparison method. In this method the value (amplitude) of duty cycle is compared with that of a unit amplitude sawtooth waveform. If the value of duty cycle is greater than the sawtooth then a high signal is 


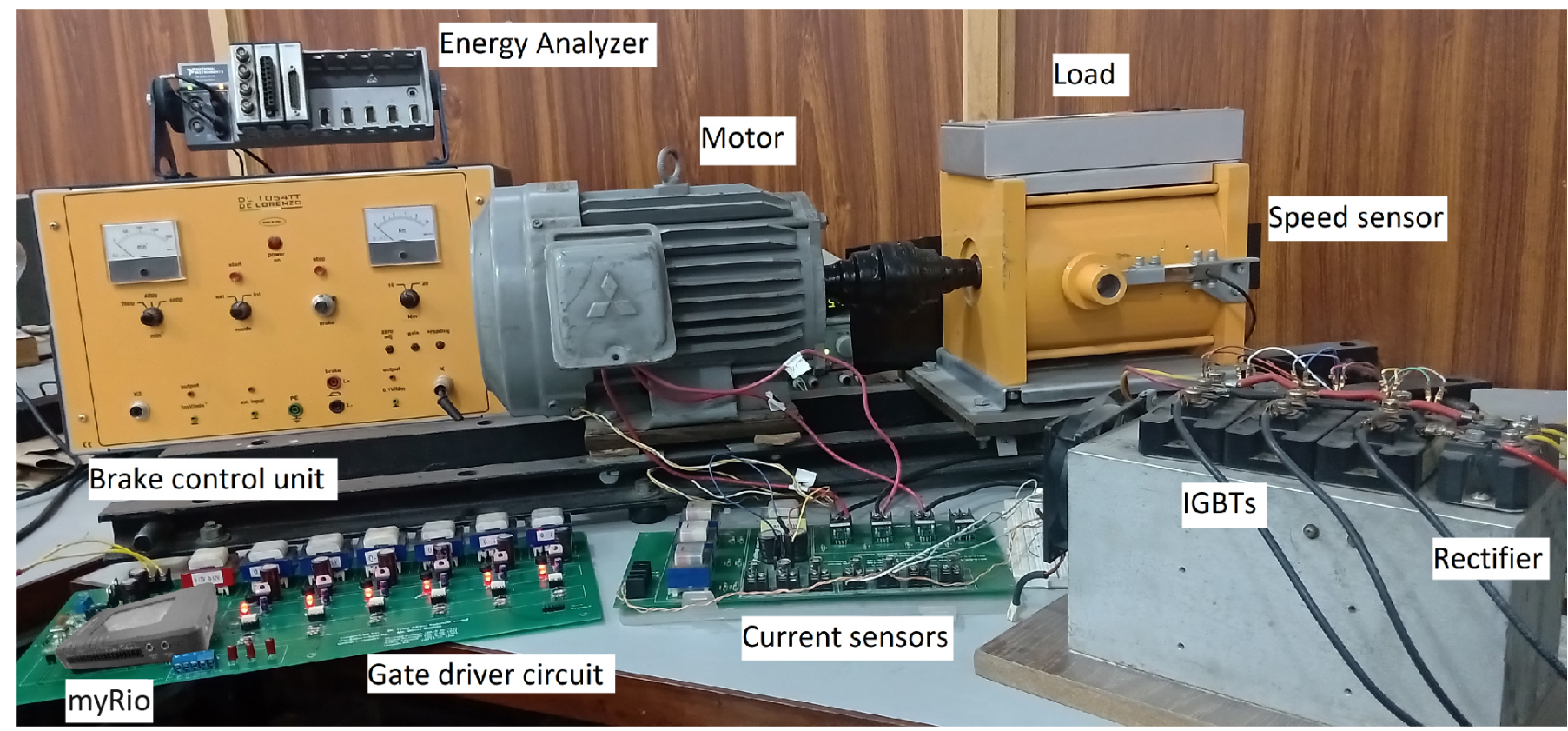

Fig. 5: Test bed for demonstration of SVPWM

generated otherwise a low signal is generated. With the varying amplitude and frequency of duty cycle, a pattern of gate signals is generated. These gate signals are fed into the gate driver which in turn form a sinusoidal output of the inverter. This phenomenon is demonstrated in Figure 8.

\section{Inverter outputs}

The outputs of the 3-phase inverter at values $0.3,0.5$ and 0.7 of the modulation index are shown in Figures 9, 10 and 11 respectively. It should be noted that the value of modulation index is always kept between 0 and 1 .

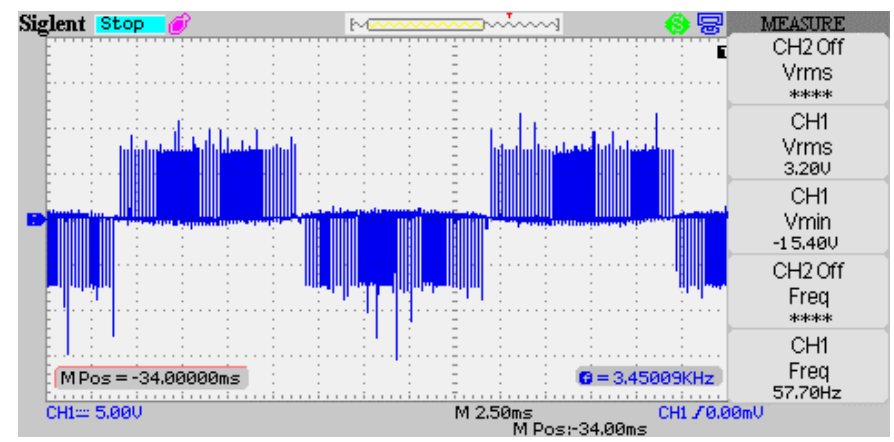

Fig. 9: Output of inverter at modulation index 0.3

\section{Phase voltages}

A bandpass RC filter was connected across the inverter to make the sinusoidal waveform from the inverter visible. In Figure 12 two phase voltages $\mathrm{V}_{a b}$ and $\mathrm{V}_{b c}$ can be observed.

\section{E. Application on motor drive}

As mentioned before, the SVPWM was applied to a 750 Watt induction motor through a gate driver and was controlled

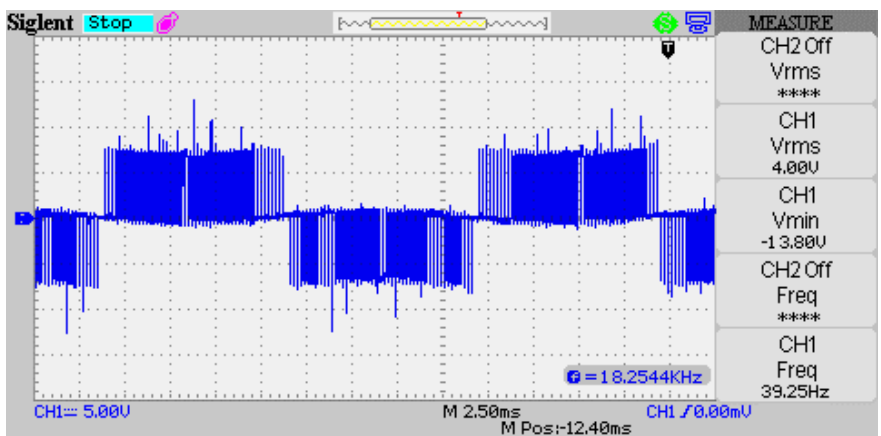

Fig. 10: Output of inverter at modulation index 0.5

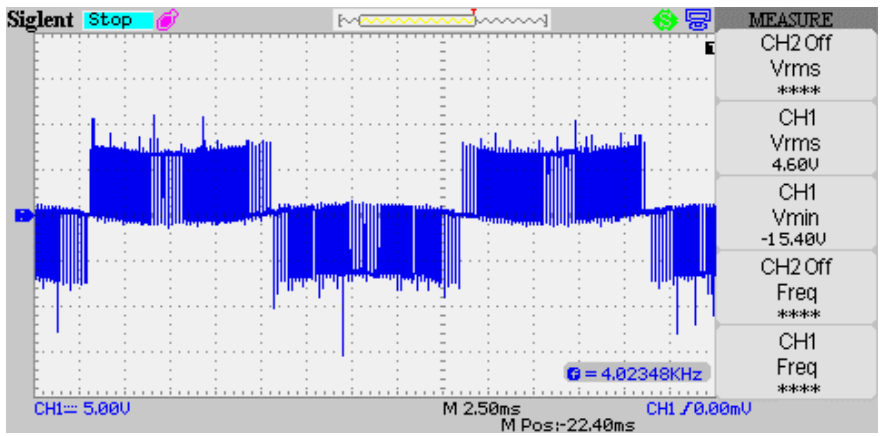

Fig. 11: Output of inverter at modulation index 0.7

through FOC. The results of this practical implementation are shown in Figure 13. In this figure, the system response to various input values can be observed. The variable "Reference Speed" represents the desired speed of the motor and "Actual Speed" is the actual system response. 


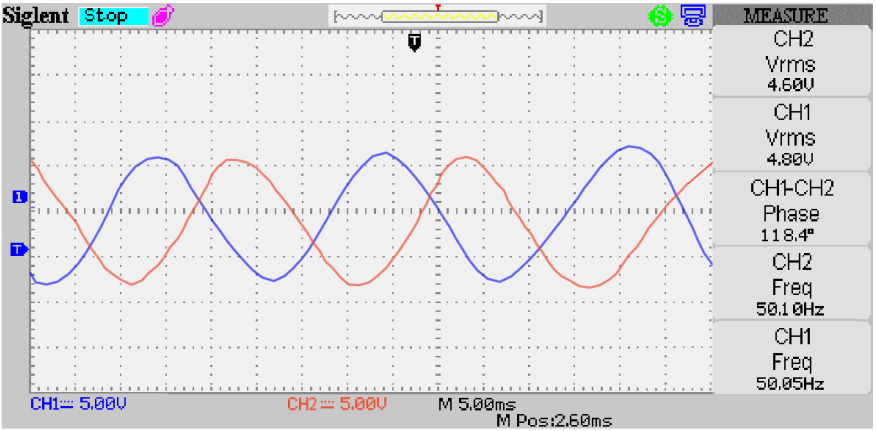

Fig. 12: Filtered phase voltages $\mathrm{V}_{a b}$ and $\mathrm{V}_{b c}$

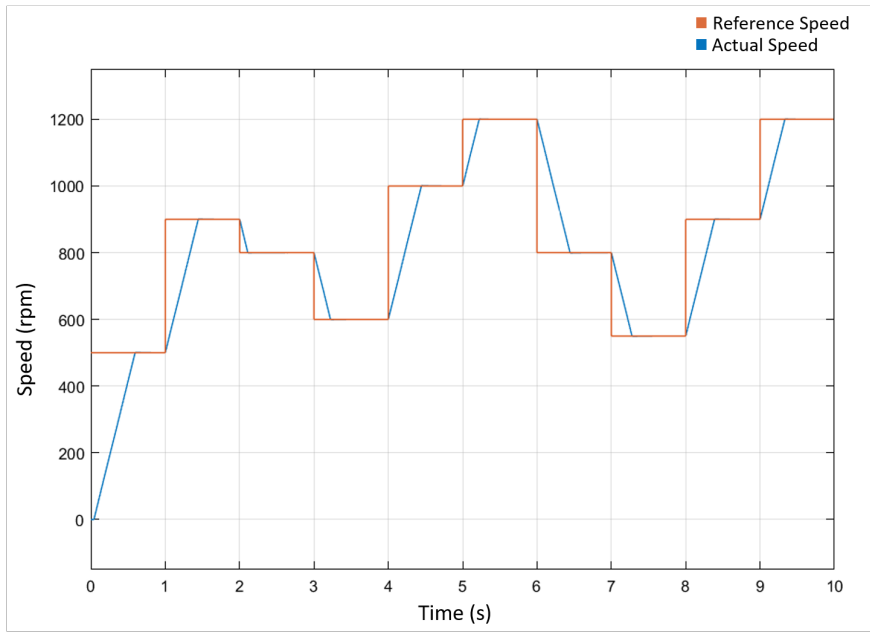

Fig. 13: Field oriented control motor response

\section{CONCLUSION}

SVPWM is an important inversion technique for power electronics applications. However, it is a complex algorithm and difficult for an undergraduate student to grasp its concepts. Similarly, students also find it difficult to implement it in a lab. An effective technique to grasp the concepts of complex algorithms is to make use of SFCs. Furthermore, developing codes of these complex algorithms in form of graphical programs following their respective SFCs make their implementation easier as well. For these purposes, LabVIEW and myRio are effective tools which make understanding and implementing complex algorithms quite tractable.

In this paper, we have presented an educational way for undergraduate students to understand complex algorithms by using structured flow charts and implement them using graphical programming.

\section{ACKNOWLEDGEMENT}

We would like to thank National Instruments (NI) Pakistan for the support they have provided in form of the technical resources including LabVIEW and myRio for this paper.

\section{REFERENCES}

[1] M. H. Rashid, "DC-AC Converters," in Power Electronics: Devices, Circuits and Applications. Boston: Pearson, 2014, ch. 6.7.4, pp. 347-359.
[2] D. A. Scanlan, "Structured flowcharts outperform pseudocode: an experimental comparison," in IEEE Software, vol. 6, no. 5, pp. 28-36, Sept. 1989, doi: 10.1109/52.35587.

[3] Rahimi E., Barendsen E., Henze I., ’Identifying Students' Misconceptions on Basic Algorithmic Concepts Through Flowchart Analysis" in: Focus on learning programming 10th International Conference on Informatics in schools, ISSEP 2017. Lecture Notes in Computer Science, vol 10696, Helsinki, Finland, November 13-15, 2017. Accessed on Jan. 3, 2022. [Online]. Available: https://doi.org/10.1007/978-3-319-71483-7_13

[4] M. S. Hall, "Raptor: nifty tools", J. Comput. Sci. Coll., vol. 23(1) pp. 110-111, Oct. 2007.

[5] D. A. Scanlan, "Should Short Relatively Complex Algorithms Be Taught Using Both Graphical and Verbal Methods: Six Replications", Proc. SIGCSE Tech. Symp. Computer Science Education, pp. 185-189, 1988.

[6] M. C. Carlisle, T. A. Wilson, J. W. Humphries, S. M. Hadfield, "RAPTOR: A visual programming environment for teaching algorithmic problem solving", in Proc. 36th SIGCSE, St. Louis, Missouri, USA, February 23-27, 2005, pp. 176-180. DOI: 10.1145/1047344.1047411

[7] P. Wright and F. Reid, "Written Information: Some Alternatives to Prose for Expressing the Outcomes of Complex Contingencies", J. Applied Psychology, pp. 160-166, Feb. 1973.

[8] B. Shneiderman, "Experimental Investigations of the Utility of Detailed Flowcharts in Programming", Comm. ACM, pp. 373-381, June 1977.

[9] Yong-Gyun Ghim, "Allocated Flow Diagramming: A Structured Process and Methods for Teaching Interactive Product Prototyping in Industrial Design", Archives of Design Research, vol. 34, pp. 7, 2021.

[10] J. Zhang, B. Meng, L. Zou, Y. Zhu, G. Hwang, "Progressive flowchart development scaffolding to improve university students' computational thinking and programming self-efficacy", Interactive Learning Environments, pp. 1, 2021.

[11] A. A. Khwaja and J. E Urban, "Syntax-directed Editing Environments: Issues and Features", Proc. 1993 ACM SIGGAP symposium on Applied Computing, 1993, pp.230-237.

[12] B. Price, R. Baecker and I. Small, "An Introduction to Software Visualization", in Software Visualization: Programming as a multimedia Experience, Cambridge, MIT Press, 1997, pp. 3-28.

[13] S. Xinogalos, "Using flowchart-based programming environments for simplifying programming and software engineering processes," 2013 IEEE Global Engineering Education Conference (EDUCON), 2013, pp. 1313-1322, doi: 10.1109/EduCon.2013.6530276.

[14] B. Calloni and D. Bagert, "Iconic Programming Proves Effective for Teaching the First Year Programming Sequence', ACM SIGSCE '97 CA, USA, 1997, pp. 262-266.

[15] T. Crews and U. Ziegler, "The Flowchart Interpreter for Introductory Programming Courses.”. Proc. FIE '98 Conference, 1998, pp. 307-312.

[16] U. Ziegler and T. Crews, "An Integrated Program Development Tool for Teaching and Learning How to Program", ACM, SIGSCE '99 3/99 New Orleans, LA, USA, 1999, pp. 276-280.

[17] Daniela Giordano, Francesco Maiorana, "Teaching algorithms: Visual language vs flowchart vs textual language", Global Engineering Education Conference (EDUCON) 2015 IEEE, pp. 499-504, 2015.

[18] National Instruments, LabVIEW Student Software Suite, LabVIEW Student Software Suite Spring 2020, May 15, 2020. Accessed on: Nov 18, 2021. [Online]. Available: https://www.ni.com/en$\mathrm{lb} /$ support/downloads/software-products/download.labview-studentsoftware-suite.html\#352831

[19] National Instruments, What Is LabVIEW?. Accessed on: Nov 18, 2021. [Online]. Available: https://www.ni.com/en-lb/shop/labview.html

[20] E. Hendawi, F. Khater and A. Shaltout, "Analysis, Simulation and Implementation of Space Vector Pulse Width Modulation Inverter", in Proc. 9th WSEAS Int. Conf. on Applications of Electrical Engineering, Cairo Univesity, Giza, Egypt, 2006, pp. 124-131. 